\title{
Methylene Blue Dye Adsorption onto Polyoxometalate Ionic Liquid Supported on Bentonite: Kinetic, Equilibrium and Thermodynamic Studies
}

\author{
Norah Alsubaie, Rawan Alshamrani, Doaa Domyati, Nadiyah Alahmadi, Fatma Bannani \\ Department of Chemistry, College of Science, University of Jeddah, Jeddah, Saudi Arabia \\ Email: fmdriss@uj.edu.sa
}

How to cite this paper: Alsubaie, N., Alshamrani, R., Domyati, D., Alahmadi, N. and Bannani, F. (2021) Methylene Blue Dye Adsorption onto Polyoxometalate Ionic Liquid Supported on Bentonite: Kinetic, Equilibrium and Thermodynamic Studies. Open Journal of Physical Chemistry, 11, 106-127. https://doi.org/10.4236/ojpc.2021.112006

Received: April 23, 2021

Accepted: May 23, 2021

Published: May 26, 2021

\section{Copyright $\odot 2021$ by author(s) and} Scientific Research Publishing Inc. This work is licensed under the Creative Commons Attribution International License (CC BY 4.0).

http://creativecommons.org/licenses/by/4.0/

\section{(c) (i) Open Access}

\begin{abstract}
The potential of polyoxometalate ionic liquid POM-IL supported on low-cost and available eco-friendly Saudi raw bentonite in the adsorption of MB cationic dye was investigated. For this purpose, $\mathrm{TOA}_{\mathrm{x}}\left[\alpha-\mathrm{XW}_{11} \mathrm{O}_{39}\right] @$ Bentonite $(\mathrm{X}$ $=\mathrm{Si}, \mathrm{P} ; \mathrm{TOA}=$ TetraOctylAmmonium), namely SWB and PWB were prepared and characterized by IR, XRD, XRF, SEM, TEM and BET. Batch adsorption experiments showed that SWB and PWB have higher adsorption capacity than the raw bentonite with an enhancement of about $37 \%$ for SWB. The adsorption capacities of both SWB and PWB improved with increasing contact time and temperature and decreased with higher salt concentration in solution. The $\mathrm{pH}$ is shown to have insignificant effect on the adsorption of $\mathrm{MB}$ onto SWB and PWB. This result is quite meaningful in the adsorption process application since it makes $\mathrm{pH}$ complicated adjustment of the discharged contaminated water before treatment unnecessary. The Kinetic study expressed that the pseudo-second-order model described the adsorption process better than the pseudo first order. The experimental isotherm data were found to fit the Langmuir model compared to the Freundlich model with a maximum adsorption capacity $277.78 \mathrm{mg} / \mathrm{g}$ and 113.6 for PWB and SWB respectively. The thermodynamic parameters illustrated that the adsorption process was favorable, spontaneous and endothermic.
\end{abstract}

\section{Keywords}

Adsorption, Bentonite, Polyoxometalates, Ionic Liquid, Wastewater Treatment

\section{Introduction}

Water pollution became the most challenging environmental issues in many 
countries, due to the industrial rapid development [1] [2]. Dyes as worst type of water pollutants [3] [4] are toxic and have an important ecological impact on ecosystem due to their strong hazard, bioaccumulation, and environmental persistence [5].

Discharge of dyes from various industrial sources such as textile, paper, food and cosmetics without treatment into the water bodies has a badly effect on ecosystem [6] [7].

Dyes can be divided into several categories, whether anionic or cationic dyes. Methylene Blue, as a typical cationic dye, was predominantly selected as a model compound to examine the adsorption process due to its wide range application in textile industries [4] [8].

A variety of conventional techniques consisting of physical, physicochemical and biological treatment have been used for the removal of dyes [9] [10] [11] [12].

Adsorption as, physicochemical treatment, is considered a technique of choice due to its low-cost, effectiveness, and easy adaptation [13].

Polyoxometalates POMs as transitional metal-oxygen clusters, are a class of inorganic compounds having tunable properties and versatile applications in different fields such as catalysis, materials science, medicine... [14] [15]. The Polyoxometalates clusters can be associated with massive organic cations to give versatile liquid materials (POM-IL) and offer several properties required for water decontamination [16] [17] [18]. On the other hand, POMs have low surface area; this disadvantage can be overcome by incorporation of the POM in different stable porous supports by formation of various composites.

Several groups have reported some adsorbents for water purification from dyes which include activated carbon, fly ash, zeolite, red mud and polymers. These adsorbents have many drawbacks such as high cost and difficult regeneration and long time to achieve adsorption equilibrium, thus limiting the application use of adsorption method in dye removal in large scale. Bentonite can be used as potential support, because it has the advantages to be naturally abundant, inexpensive, eco-friendly, having good surface area and good cation exchange capacity [19] [20].

This work aims to assess the potential for using a new adsorbent based on supported POM-IL on bentonite in the removal of MB dye from aqueous solutions. The adsorption characteristics will be investigated under operating variables, such as contact time, adsorbent mass, initial $\mathrm{MB}$ concentration, $\mathrm{pH}$ solution and temperature. Isotherm, kinetics and thermodynamic studies were performed in order to evaluate the adsorption process that controlled the removal of $\mathrm{MB}$ from aqueous solutions.

\section{Materials and Methods}

\subsection{Materials}

Bentonite was collected from Khulays bentonite deposit, $95 \mathrm{~km}$ north of Jeddah, 
Saudi Arabia. All reagents used were analytical grade and were not subjected to additional purification. Analytical grade Methylene Blue (MB) $\left(\mathrm{C}_{16} \mathrm{H}_{18} \mathrm{ClN}_{3} \mathrm{~S}\right)$, supplied from Fluka was used without further purification. Sodium tungstate $\mathrm{Na}_{2} \mathrm{WO}_{4}$, salts, namely sodium chloride $(\mathrm{NaCl})$, potassium chloride $(\mathrm{KCl})$ and sodium nitrate $\left(\mathrm{NaNO}_{3}\right)$ were all obtained from J.T. Baker. Distilled water was used to prepare all aqueous solutions in the study.

\subsection{Adsorbent Preparation}

The adsorbent preparation was preformed according to three steps.

First monolacunary Keggin-type polyoxometalates preparation, then preparation of polyoxometalate Ionic liquid POM-IL by metathesis reaction, followed by impregnation of the raw clay.

\subsubsection{Synthesis of $\mathrm{K}_{8}\left[\alpha-\mathrm{SiW}_{11} \mathrm{O}_{39}\right] \cdot 13 \mathrm{H}_{2} \mathrm{O}$}

The polyanion was prepared according to the reported literature procedure [18]. $\mathrm{Na}_{2} \mathrm{WO}_{4} \cdot 4 \mathrm{H}_{2} \mathrm{O}(182 \mathrm{~g}, 0.55 \mathrm{~mol})$ is dissolved in distilled water $(300 \mathrm{~mL})$ and the solution is heated to reflux. Aqueous $4 \mathrm{M} \mathrm{HCl}(165 \mathrm{~mL})$ is added dropwise under vigorous stirring to the heated solution over a period of $30 \mathrm{~min}$. Crucially, any precipitate (tungstic acid) formed is allowed to re-dissolve before further acid addition. An aqueous solution of sodium metasilicate $(11 \mathrm{~g}, 50 \mathrm{mmol}$ in $100 \mathrm{~mL}$ distilled water) is added followed by quick addition of aqueous $4 \mathrm{M} \mathrm{HCl}(50 \mathrm{~mL})$, giving a solution $\mathrm{pH}$ of 5.0. The solution is refluxed for $1 \mathrm{~h}$.

After cooling to room temperature, $\mathrm{KCl}(150 \mathrm{~g})$ is added, and a colorless precipitate is formed. The solid product is collected by filtration, washed with two $50 \mathrm{~mL}$ portions of aqueous $\mathrm{KCl}$ solution $(1 \mathrm{M})$ followed by two $30 \mathrm{~mL}$ portions of cold water. The crude product is recrystallized from water, filtered and the colorless crystalline product is dried in the desiccator under vacuum.

\subsubsection{Synthesis of $\mathrm{K}_{7}\left[\alpha-\mathrm{PW}_{11} \mathrm{O}_{39}\right] \cdot 13 \mathrm{H}_{2} \mathrm{O}$}

The undecatungstophosphate was prepared using the same method according to the literature procedure. [18]

In $300 \mathrm{~mL}$ beaker, $54 \mathrm{~g}$ of $\mathrm{Na}_{2} \mathrm{WO}_{4} \cdot 2 \mathrm{H}_{2} \mathrm{O}\left(0.164\right.$ mole) and $2.1 \mathrm{~g}$ of $\mathrm{Na}_{2} \mathrm{HPO}_{4}$ $(0.015$ mole $)$ were dissolved in $150 \mathrm{~mL}$ distilled water. The solution was heated and stirred at $90^{\circ} \mathrm{C}$ and $60 \mathrm{~mL}$ of $(4 \mathrm{M}) \mathrm{HCl}$ was added dropwise by burette over one hour. The final $\mathrm{pH}$ of the solution should be adjusted to $5.5-6.5$, if necessary. The solution was kept at $90^{\circ} \mathrm{C}$ for another hour and the $\mathrm{pH}$ was checked again. If the $\mathrm{pH}$ remained unchanged, $21 \mathrm{~g}$ of solid $\mathrm{KCl}$ was added to the solution and dissolved. Upon cooling to $0^{\circ} \mathrm{C}$ the white precipitate was isolated from the solution, and it was recrystallized twice from hot water. The salt was checked with IR and EDS and the results were in agreement with those reported in literature.

\subsubsection{Synthesis of $\mathrm{TOA}_{\mathrm{X}}\left[\alpha-\mathrm{XW}_{11} \mathrm{O}_{39}\right](\mathrm{X}=\mathrm{Si}, \mathrm{P})$}

In a round-bottom flask, a solution of $\mathrm{K}_{\mathrm{y}}\left[\alpha-\mathrm{XW}_{11} \mathrm{O}_{39}\right] \cdot \mathrm{xH}_{2} \mathrm{O}$ (1.00 eq.) was dissolved in $50 \mathrm{~mL}$ of water, heated to $50^{\circ} \mathrm{C}$ and a solution of adequate amount of TOA-Br $\left(8.00\right.$ eq for $\left\{\mathrm{SiW}_{11} \mathrm{O}_{39}\right\}$ and 7.00 for $\left.\left\{\mathrm{PW}_{11} \mathrm{O}_{39}\right\}\right)$ in toluene $(80 \mathrm{~mL})$ was 
added. The mixture was vigorously stirred for 5 minutes and the organic layer was separated. After removal of the solvent under reduced pressure, the light yellow highly viscous liquid was solvent-stripped once with $50 \mathrm{~mL}$ toluene and three times with $50 \mathrm{~mL}$ chloroform.

\subsubsection{Synthesis of $\mathrm{TOA}_{8}\left[\alpha-\mathrm{XW}_{11} \mathrm{O}_{39}\right] @ B e n t o n i t e$} ( $X$ = Si Namely SWB, X = P Namely PWB)

$0.5 \mathrm{~g}$ of $\left[\mathrm{N}\left(\mathrm{C}_{8} \mathrm{H}_{17}\right)_{4}\right]_{\mathrm{y}} \mathrm{XW}_{11} \mathrm{O}_{39}$ was dissolved in $50 \mathrm{~mL}$ of acetone and then $4 \mathrm{~g}$ of Bentonite were added. The suspension was gently shaken for 30 minutes and the solvent was removed by rotary evaporator. Further $50 \mathrm{~mL}$ of acetone were added, and the shaking/solvent removal procedure was repeated three times. The final product was obtained as a solid, free-flowing powder. The POM-IL loading corresponds to $12.5 \mathrm{wt} \%$.

\subsection{Characterizations of SWB and PWB}

Information on the crystalline structures was obtained through XRD analysis (powder PXRD diffractometer (Model Equinox 1000-INEL (France) with Co Ko $(\lambda=1.7890 \AA$ ) radiation at $30 \mathrm{kV}$ and $30 \mathrm{~mA}$. Comparison of POMs to the parent Keggin structure was performed using the reference data in the ICDD (international Centre for Diffraction Data) database. Sample morphology was investigated by means of field emission scanning electron microscopy (FEG-SEM, Quanta FEG450. FEI, the Netherlands) using an ETD Everhart Thornley detector (High Vacuum mode), a solid-state backscattering electron detector (VCD) and EDS detector (XFLASH6-30, Brucker) for the determination of elemental composition of the samples. The dispersion as well as size of POMs particles on the Bentonite support and the layered structure of Bentonite and POM-IL@Bentonite were confirmed by transmission electron microscope (TEM) using a Tecnai G2 F20 Super Twin (FEI, the Netherlands) with a LaB6 source at $200 \mathrm{kV}$. The electron microscope was fitted with an EDS detector used for elemental analysis. The nanoprobe STEM imaging were performed with a HADAF detector. Gatan camera $200 \mathrm{kV}, 2 \mathrm{kx} 2 \mathrm{k}$ resolution was used to collect TEM images. The TEM, HRTEM, STEM and EDS data were collected and treated by using the TIA software (Tecnai Imaging and Analysis software version 1.9.162) and Gatan Micrograph Software version 2.3 .

POM-IL and bentonite surface functional groups were investigated using Fourier transform infrared spectroscopy (FTIR) analysis (Bruker Tensor II spectrometer).

Nitrogen sorption was used to investigate the specific surface area (BET method), specific pore volume and pore diameter (BJH method) of the raw bentonite and POM-SIL modified bentonite using NOVA (2200 e) high-speed surface area and pore size analyzer.

\subsection{Preparation of Adsorbate}

Stock solution of $1000 \mathrm{mg} / \mathrm{L}$ was prepared by dissolving a $1 \mathrm{~g}$ of Methylene Blue 
in $1 \mathrm{~L}$ of distilled water. The experimental solution was prepared by using distilled water for diluting the stock solution. The concentration of Methylene Blue dye before and after adsorption were determined using UV spectrophotometer, GENESYS 10S UV-VIS. The $\lambda_{\max }$ of MB dye has been estimated at $665 \mathrm{~nm}$ as shown in Figure 1.

\subsection{Adsorption Experiment}

\subsubsection{Batch Method}

Adsorption test for $\mathrm{MB}$ removal from aqueous solutions was examined using adsorption batch experiments to explore the adsorption properties and the factors influencing the adsorption. Batch experiments were performed by varying contact time, mass of adsorbents, concentration of dyes, $\mathrm{pH}$, ionic strength and temperature.

The following conditions were preserved for the different sets of experiments:

1) The effect of $\mathrm{pH}$ was conducted in the range from 2.0 to $10.0,30 \mathrm{mg}$ of SWB and $40 \mathrm{mg}$ of $\mathrm{PWB}, 100 \mathrm{~mL}$ solution volume, $50 \mathrm{ppm} \mathrm{MB}$ concentration and $\mathrm{T}=298 \mathrm{~K} . \mathrm{HCl}(0.01 \mathrm{M})$ or $\mathrm{NaOH}(0.01 \mathrm{M})$ was added to set the desired $\mathrm{pH}$ value.

2) Effect of contact time was carried out through the time intervals (10, 20, 30, 40, 50, and $60 \mathrm{~min}$ ), $30 \mathrm{mg}$ of adsorbent, $100 \mathrm{~mL}$ solution, $50 \mathrm{ppm} \mathrm{MB}$ concentration, $298 \mathrm{~K}$, initial non modified $\mathrm{pH}$.

3) The effect of adsorbent mass was examined using different doses (20, 30, 40 and $50 \mathrm{mg}$ ) of adsorbent, initial non modified $\mathrm{pH}$, time $60 \mathrm{~min}, 50 \mathrm{ppm} \mathrm{MB}$ concentration, $100 \mathrm{~mL}$ solution volume, and temperature $298 \mathrm{~K}$.

4) The effect of initial concentration was conducted using 50, 100, 150 and 200 $\mathrm{mg} / \mathrm{L}$ of $\mathrm{MB}$, initial non modified $\mathrm{pH}$, time $60 \mathrm{~min}$, adsorbent mass $30 \mathrm{mg}$ of SWB and $40 \mathrm{mg}$ of PWB, and temperature $298 \mathrm{~K}$.

5) The Effect of ionic strength was conducted by adding $\mathrm{NaCl}, \mathrm{KCl}$ and $\mathrm{Na}$ $\mathrm{NO}_{3}$ salts at different concentrations ranging from 0.1 to $0.4 \mathrm{M}$, initial non modified $\mathrm{pH}$, time $60 \mathrm{~min}, 50 \mathrm{ppm} \mathrm{MB}$ concentration, $100 \mathrm{~mL}$ solution volume, and temperature $298 \mathrm{~K}$.

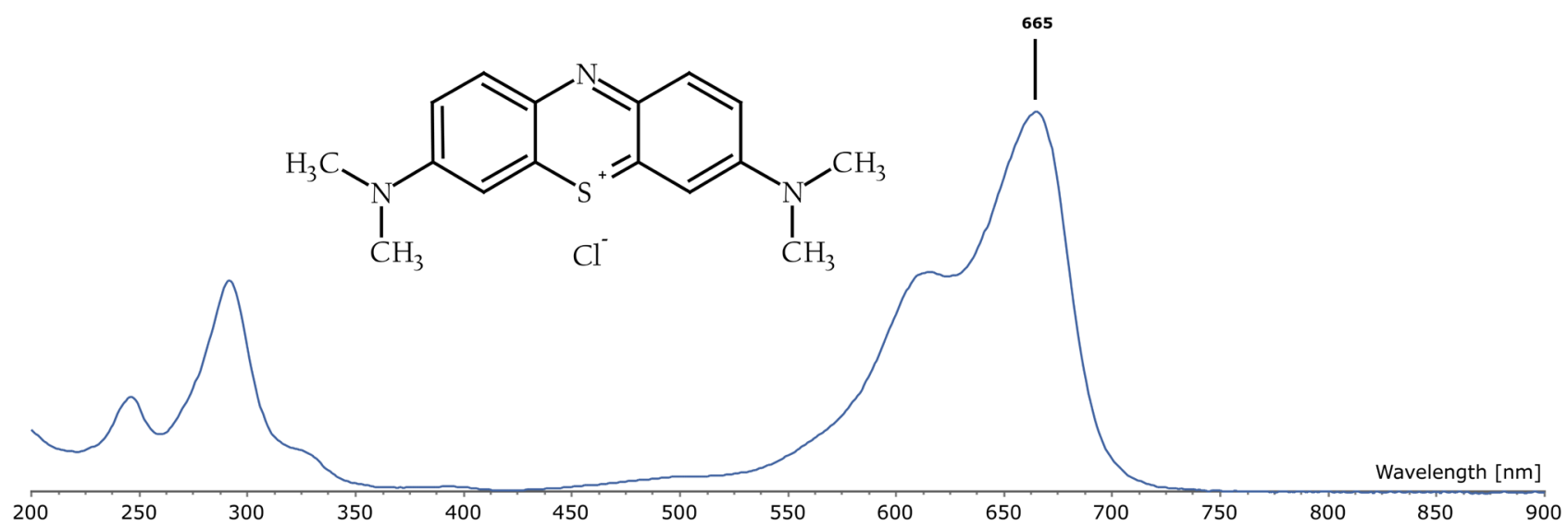

Figure 1. Absorbance of methylene blue $(\mathrm{MB})$ at $\lambda_{\max }=665 \mathrm{~nm}(\mathrm{C}=5 \mathrm{mg} / \mathrm{L})$. 
6) The influence of temperature on the adsorption process was studied under different temperatures of 298, 313, 328 and $343 \mathrm{~K}$, initial non modified $\mathrm{pH}$, time 60 $\mathrm{min}, 50 \mathrm{mg} / \mathrm{L} \mathrm{MB}$ concentration, adsorbent mass $20 \mathrm{mg}$, solution volume $100 \mathrm{~mL}$.

In all experiments, a water bath shaker at $300 \mathrm{rpm}$ was used to set the desired temperature and duration of the studied mixture. After adsorption, the dye was kept apart from the adsorbent by centrifugation with $3000 \mathrm{rpm}$ speed and use UV-VIS spectrophotometric technique to determine the residual concentration $\mathrm{C}$ based on Beer-lambert equation.

\subsubsection{Data Processing}

The percentage removal and adsorption capacity at time $\left(Q_{t}\right)$ were calculated by using Equations (1) and (2), respectively.

$$
\begin{gathered}
R \%=\frac{C_{0}-C_{f}}{C_{0}} \times 100 \\
Q_{t}=\frac{C_{0}-C_{f}}{m} \times V
\end{gathered}
$$

$C_{0}$ and $C_{f}$ initial and final concentrations $(\mathrm{mg} / \mathrm{L})$ of dye solutions. $V$ : volume (L). m: mass ( $\mathrm{g}$ ) of the adsorbent.

\subsection{Reusability Test}

The reusability of the adsorbent was examined for four adsorption cycles. Adsorption was performed in $50 \mathrm{mg} / \mathrm{L}$ Methylene Blue (MB) solution with $400 \mathrm{mg}$ absorbent at room temperature, after removing $\mathrm{MB}$ dye, the MB-loaded adsorbent was washed with $80 \mathrm{~mL}$ of $5 \% \mathrm{HCl} /$ ethanol (v/v) and washed twice with distilled water for 15 minutes and then dried at $120^{\circ} \mathrm{C}$ for reuse in a fresh contaminated solution.

\section{Results and Discussion}

\subsection{Characterization of SWB and PWB}

\subsubsection{Fourier Transform Infrared (FTIR)}

The FTIR spectra of raw bentonite, SWB and PWB in the range of $4000-400$ $\mathrm{cm}^{-1}$ were shown in Figure 2. The FTIR transmittance bands in the low frequency region $\left(1200-400 \mathrm{~cm}^{-1}\right)$ of the modified Bentonite and raw Bentonite are largely comparable indicating that the clay mineral has not changed upon modification by polyoxometalate.

Absorption due to Al-O-Si bending at $527 \mathrm{~cm}^{-1}$, Si-O-Si bending at $468 \mathrm{~cm}^{-1}$, and Al-Al-OH bending at $914 \mathrm{~cm}^{-1}$ confirm the presence of montmorillonite [21] [22]. The very strong characteristic peak observed at $1032 \mathrm{~cm}^{-1}$ was ascribed to asymmetric stretching vibrations of Si-O-Si bonds. The broad band in the $3430-3623 \mathrm{~cm}^{-1}$ region can be ascribed to the symmetric stretching of ( $\mathrm{Si}-\mathrm{OH}$, $\mathrm{Al}-\mathrm{OH})$ structural hydroxyl groups $\mathrm{OH}$ and of the physically adsorbed water $\mathrm{OH}$. The shoulder at $3694 \mathrm{~cm}^{-1}$ and the weak band at $695 \mathrm{~cm}^{-1}$ suggest the presence of kaolinite. The absorption band at $1639 \mathrm{~cm}^{-1}$ is attributed to the 


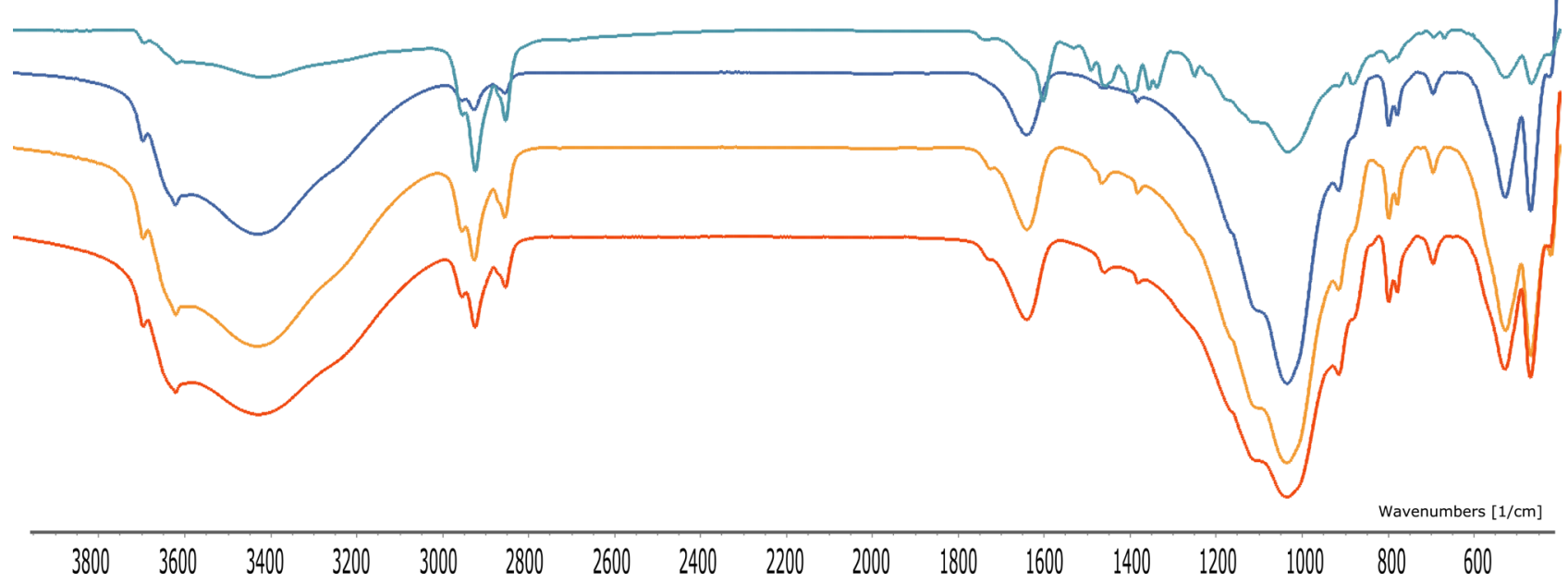

Figure 2. Infrared spectra (from top to bottom) of SWB after MB adsorption, SWB before adsorption, PWB and Bentonite.

angular vibration of the $\mathrm{OH}$ group and related to the adsorbed water and the hydration water present in the clay.

New absorption bands emerged at 2950, 2854, 1468 and $1382 \mathrm{~cm}^{-1}$ which confirm the presence of TOA cations. The fingerprint of POM is not clearly visible in FT-IR spectra of SWB and PWB due to their overlapping with FT-IR bands of Bentonite.

After adsorption of MB dye some bands appeared, such as bands at $1488 \mathrm{~cm}^{-1}$ and peaks at $1394-1335 \mathrm{~cm}^{-1}$ region related to the $-\mathrm{CH}_{3}$ and the feature conforming to the $\mathrm{C}=\mathrm{C}$ skeleton stretching at $1600 \mathrm{~cm}^{-1}$ characteristic of the aromatic ring vibrations of $\mathrm{MB}$ dye.

\subsubsection{Scanning Electron Microscope Analysis (SEM)}

The SEM images of the raw Bentonite showed an irregular porosity and disperse surface with large number of cavities Figure 3(A). In contrast, the morphology of SWB sample showed clear changing in the surficial properties of the clay Figure 3(B). The surface becomes smoother, flake like morphology with smaller cavities than raw bentonite, this result is confirmed by BET analysis. The Scanning Electron Microscopy showed that the bentonite layer-stacking structure was retained even after incorporating polyoxometalate ionic liquid into the bentonite matrix.

\subsubsection{Chemical Composition}

EDS analysis Table 1 showed that natural Saudi bentonite is mainly composed of silicon dioxide, Aluminum oxide, iron oxide, sodium oxide, in addition to calcium, magnesium, titanium and potassium oxides. Comparison of raw and modified bentonite revealed no significant change of the chemical composition of the bentonite matrix.

\subsubsection{Powder X-Ray Diffraction (PXRD)}

The X-ray patterns of raw Bentonite, PWB and SWB are illustrated in Figure 4. 


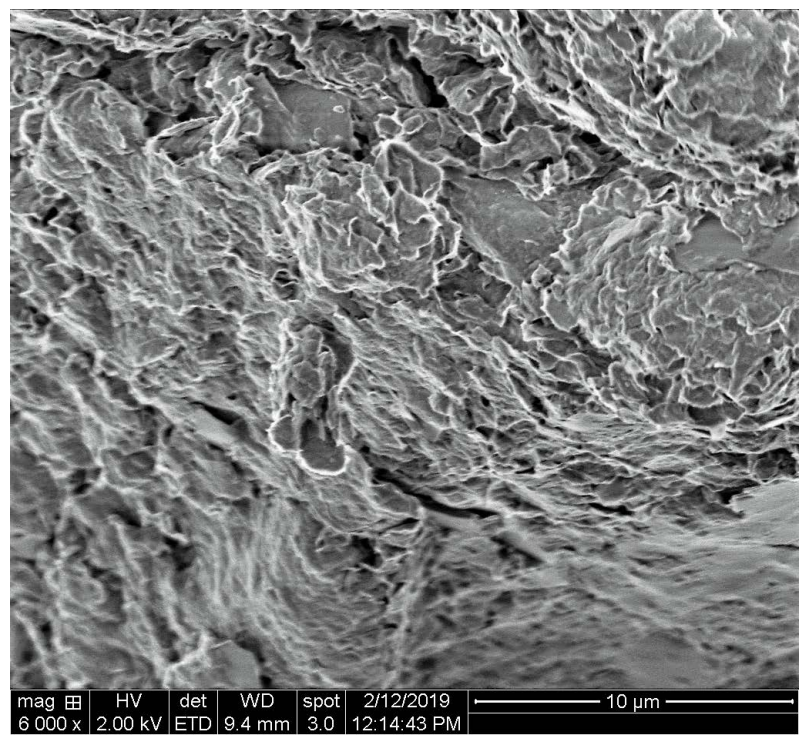

(A)

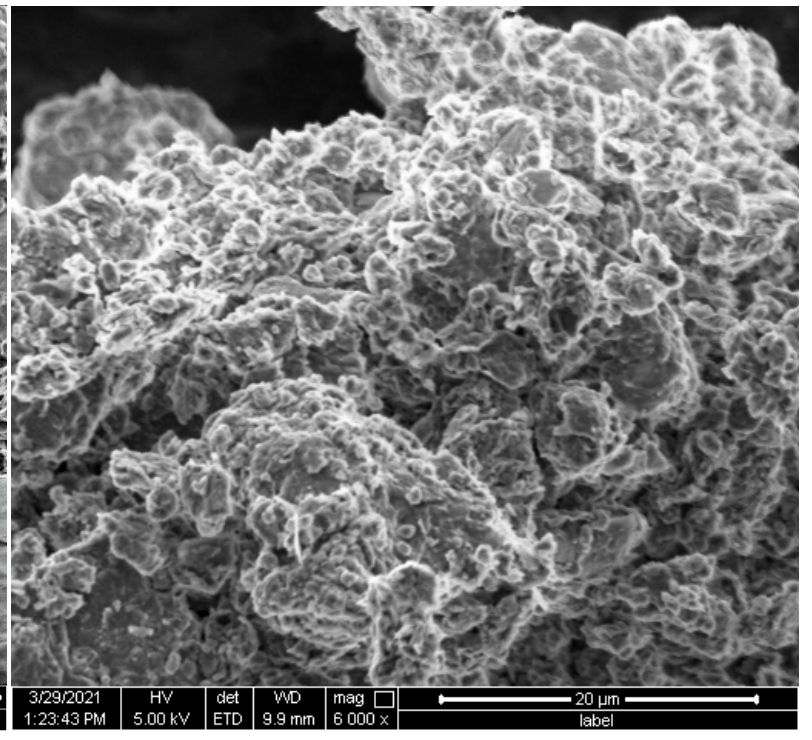

(B)

Figure 3. SEM images of (A) natural bentonite and (B) SWB.

Table 1. Chemical composition of raw Saudi bentonite and POM-IL modified bentonite.

\begin{tabular}{ccccccccc}
\hline Main constituent & $\mathrm{SiO}_{2}$ & $\mathrm{Al}_{2} \mathrm{O}_{3}$ & $\mathrm{Fe}_{2} \mathrm{O}_{3}$ & $\mathrm{MgO}$ & $\mathrm{TiO}_{2}$ & $\mathrm{Na}_{2} \mathrm{O}$ & $\mathrm{CaO}$ & $\mathrm{K}_{2} \mathrm{O}$ \\
\hline Raw Bentonite Wt\% & 59.03 & 21.59 & 9.63 & 2.95 & 1.37 & 2.83 & 1.24 & 0.66 \\
Modified Bentonite Wt\% & 58.11 & 19.58 & 10.06 & 2.15 & 1.69 & 1.43 & 1.39 & 0.63 \\
\hline
\end{tabular}

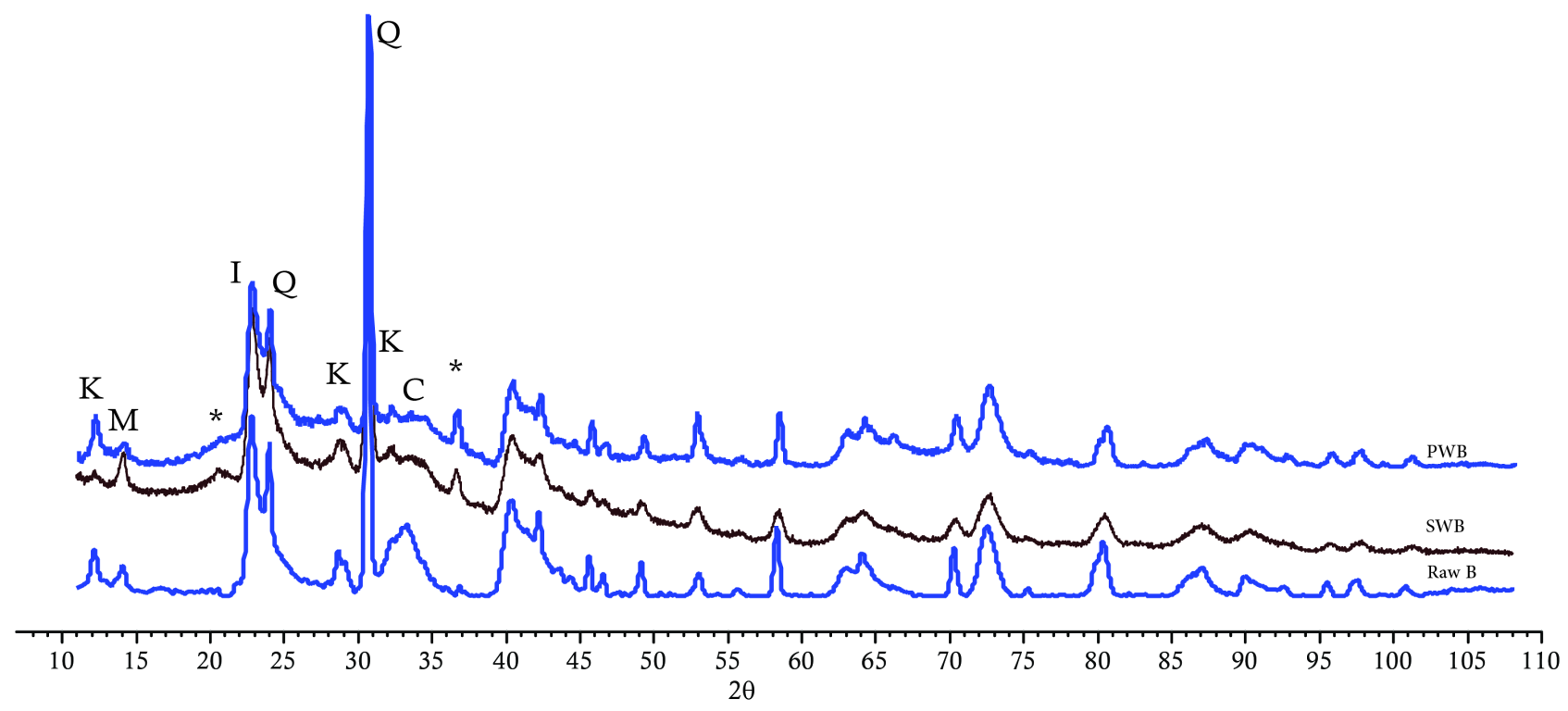

Figure 4. XRD analysis of (from top to bottom) SWB, PWB and raw bentonite $\left({ }^{*}=\right.$ pom peaks).

The XRD analysis of raw bentonite sample showed that bentonite is mainly composed of, quartz $\left(\mathrm{SiO}_{2}\right)$, calcite $\left(\mathrm{CaCO}_{3}\right)$ and Feldspar as non-clay minerals.

XRD patterns diffractograms revealed three main clay minerals, montmorillonite, kaolinite and illite. Moreover, the characteristic diffraction signals were found to be identical for both raw bentonite and (TOA) $\mathrm{XW}_{11} @$ Bentonite which 
indicate that the POM-IL remains on the surface of the clay.

The X-ray diffractogram recorded in a range of small angle $(2 \theta)$ ranging from $0^{\circ}$ to $10^{\circ}$ Figure 5 shows the presence of a characteristic diffraction peak located at $(2 \theta)=5.68^{\circ}$ from which the interlayer distance was found to be $14.08 \AA$. This peak is associated with the (001) diffraction $\left(\mathrm{d}_{001}\right)$ of the montmorillonite phase. [23] [24] The introduction of POM to the Bentonite has not affected the $d_{001}$ diffraction peak which appears at $14.86 \AA$ for SWB and $15.58 \AA$ for PWB since there is no significant expansion of interlayer space $\Delta \mathrm{d}(4.38 \AA$ and $5.05 \AA)$.

This finding confirmed that the structure of Bentonite is retained after POM-IL incorporation.

Moreover, the presence of POM in the prepared adsorbent is confirmed by the presence of structural characteristic peaks at $2 \theta .37 .20^{\circ}, 65.80^{\circ}, 66.83^{\circ}$ and $78.77^{\circ}$ in agreement with the Keggin structure [25] [26]. The data also show that quartz major component is not affected during POM incorporation to the clay.

\subsubsection{Transmission Electron Microscopy Analysis (TEM)}

TEM characterization carried out on the raw bentonite and POM modified bentonite are presented in Figure 6(A). TEM analysis confirmed the XRD results and reveal the existence of layers at basal space $\mathrm{d}_{001}=14.08 \AA$ for bentonite and $\mathrm{d}_{001}=14.75 \AA$ for POM modified bentonite. Moreover, TEM shows that POM molecules are located on the surface of Bentonite (dark spots in Figure 6(B)) and confirm the nanosized Keggin structure $(\sim 1 \mathrm{~nm})$.

\subsubsection{Nitrogen Sorption Analysis}

Nitrogen sorption was used to investigate the specific surface area (BET method), pore diameter and specific pore volume (BJH method) of the raw bentonite and

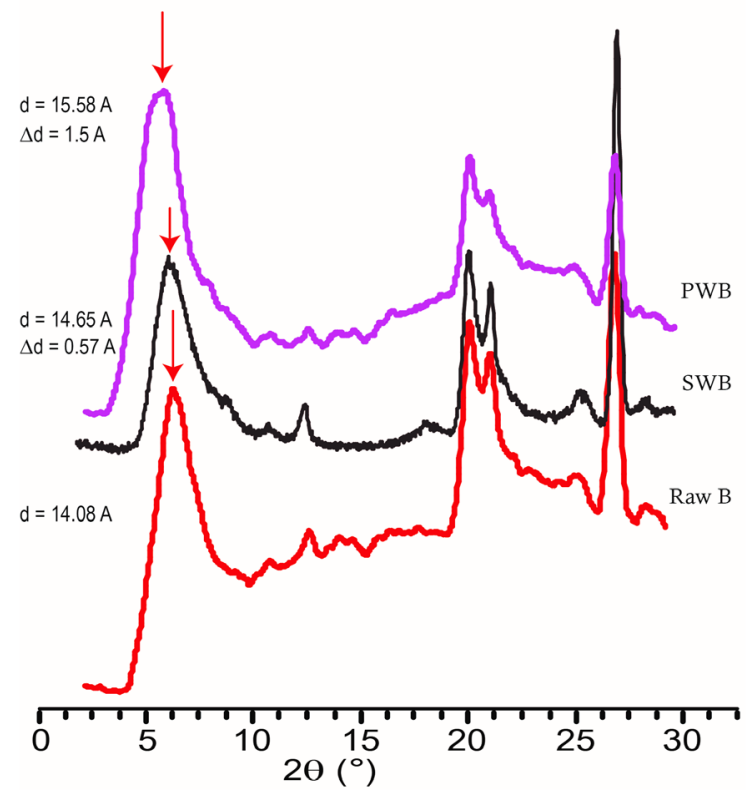

Figure 5. Low angle PXRD diffractograms of (from top to bottom) SWB, PWB and raw bentonite. 

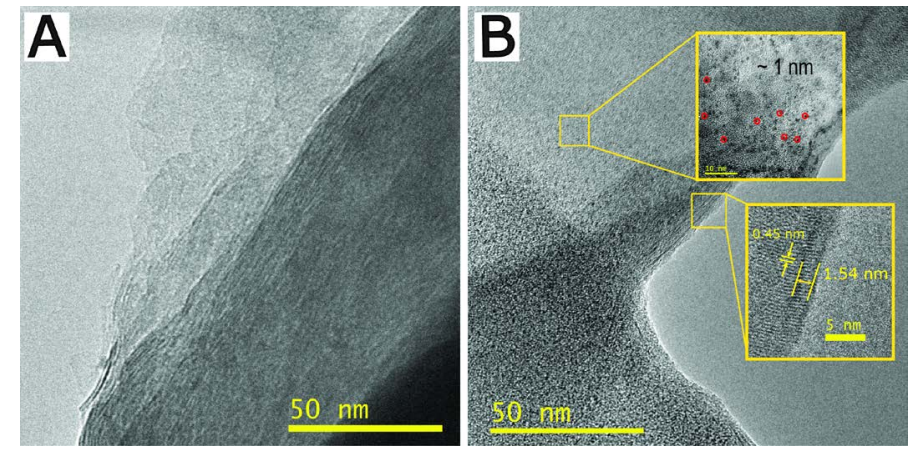

Figure 6. TEM images of: (A) Raw bentonite and (B) SWB.

Table 2. Nitrogen sorption results for non-modified bentonite and POM-IL modified bentonite.

\begin{tabular}{cccc}
\hline Samples & $\begin{array}{c}\text { Specific surface } \\
\text { area }\left(\mathrm{m}^{2} / \mathrm{g}\right)\end{array}$ & $\begin{array}{c}\text { Specific pore } \\
\text { volume }\left(\mathrm{cm}^{3} / \mathrm{g}\right)\end{array}$ & $\begin{array}{c}\text { Average pore } \\
\text { radius }(\AA)\end{array}$ \\
\hline Raw Bentonite & 59 & 0.086 & 17.60 \\
PWB & 1.16 & 0.013 & 14.83 \\
SWB & 2.32 & 0.015 & 15.58 \\
\hline
\end{tabular}

POM-IL modified bentonite to establish the consequences of POM-IL adsorption on the bentonite pore structure. The data in Table 2 show that upon POM-IL adsorption in POM-IL@bentonite, an overall reduction in pore diameter, specific pore volume and specific surface area is observed. This verifies that the POM-IL does not only coat the exterior surface but also coats the internal pore structure while leaving the pores still accessible.

\subsection{MB Adsorption Experiments}

\subsubsection{Effect of Contact Time}

The effect of contact time on Methylene Blue removal by SWB, PWB and bentonite is shown in Figure 7. It could be seen that the MB adsorption increases with increasing contact time for modified and raw bentonite and occurred in two stage: first fast stage and equilibrium stage. SWB adsorbent has higher removal than PWB during the rapid first stage and reached 93\% removal after 10 min compared to $66 \%$ for PWB for the same time. The difference can be explained by the nature of the heteroatom in the polyoxometalate which plays a role in the overall charge of the polyanion making $\left[\mathrm{SiW}_{11} \mathrm{O}_{39}\right]^{8-}$ more negative than $\left[\mathrm{PW}_{11} \mathrm{O}_{39}\right]^{7-}$ which in turn attracts more cationic MB dye since the adsorption is due to electrostatic attraction between negative adsorbent surface and positive dye molecules. The rapid MB removal during the first stage (10 $\mathrm{min})$ is due to presence of high number of available vacant sites on the adsorbent surfaces, the adsorption reached equilibrium within almost 30 min with total removal. Further increase in contact time will no longer improve the adsorption percent removal. There is also a significant difference in percent removal between raw bentonite, SWB and PWB which clearly confirms the enhancement in 
bentonite adsorptive performance with POM-IL modification.

\subsubsection{Effect of Adsorbent Mass}

The effect of adsorbent mass was studied by variation of SWB and PWB dose from 20 to $60 \mathrm{mg}$. Figure $8(\mathrm{~A})$ clearly shows that the \% removal of $\mathrm{MB}$ increased with increasing dose of adsorbents. This is due to the increasing available vacant sites which, therefore increases the percent removal. However, the adsorption capacity $\left(Q_{e}\right)$ Figure $8(B)$ decreased as the adsorbent dose increased. This is because, the large adsorbent mass effectively decreases the number of covered sites per unit mass comes down, which results in a reduced capacity.

By comparison with raw bentonite, we noticed that the capacity uptake of POM-IL bentonite for both adsorbents SWB and PWB is higher than that of raw bentonite in the range of $20-60 \mathrm{mg}$. such a result shows clearly that the incorporation of POM-IL in the bentonite matrix enhances the adsorptive capacity of the bentonite at low adsorbent dose.

\subsubsection{Effect of Concentration}

The effect of initial concentration on the removal of methylene blue on SWB,

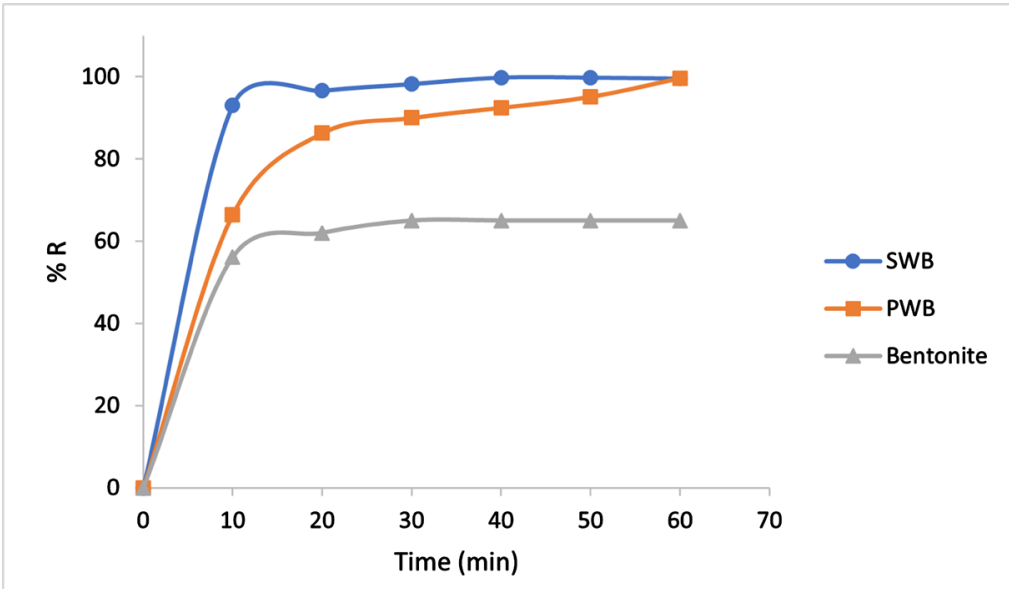

Figure 7. Effect of contact time on the adsorption of MB using SWB, PWB and bentonite.
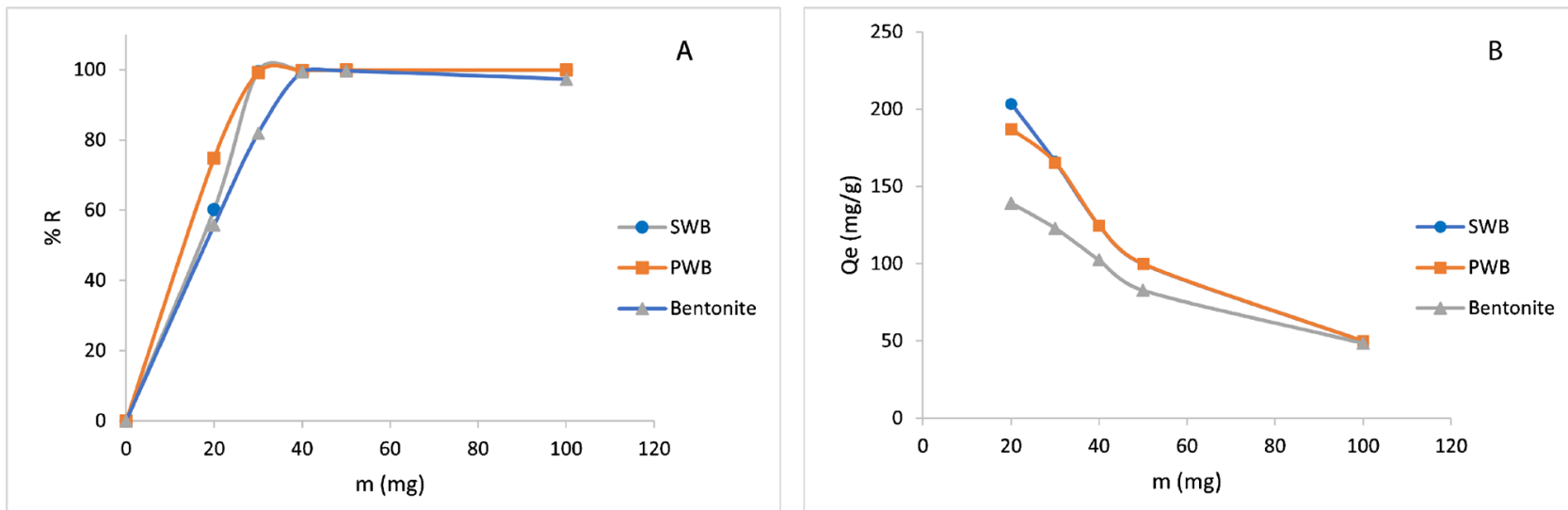

Figure 8.Effect of adsorbent mass of $\mathrm{MB}$ on SWB, $\mathrm{PWB}$ and Bentonite on the (A) \% removal, (B) adsorption capacity $Q_{\text {e. }}$ 
PWB and bentonite is studied in the range from $50-200 \mathrm{mg} / \mathrm{L}$. The results are reported in Figure 9. Several studies have documented the effect of initial dye concentration on dye uptake by clays. In most cases the increase of initial concentration resulted in an increase of the adsorption capacity and a decrease of the overall removal efficiency. In this study, the \% removal of dye decreased with increasing initial dye concentrations. At low concentration $(50 \mathrm{ppm})$, the removal reached almost $100 \%$ for both POM-IL modified bentonite and raw bentonite. Over loading of methylene blue above the saturation level did not find available vacant site resulting on the formation of accumulation of methylene blue molecule on the surface of adsorbent and the \% removal decrease. At concentrations higher than $100 \mathrm{ppm}$, SWB adsorbent has higher \% removal when compared to PWB and Bentonite which have similar results. The adsorption capacity $\left(Q_{e}\right)$ increased gradually with the increase in concentration Figure 9(A). However, at lower dye concentration, the adsorption is independent on initial concentration since the ratio of the number of $\mathrm{MB}$ cations to the number of available adsorption sites is small.


Figure 9. Effect of initial concentration Effect of initial concentration on the \% removal (A) and adsorption capacity (B).

\subsubsection{Effect of $\mathrm{pH}$}

The $\mathrm{pH}$ effect on the adsorption of MB dye on SWB and PWB was investigated in the range of $2-10$. As shown in Figure 10, there is no significant effect on the adsorption of methylene blue while changing the $\mathrm{pH}$ solution values, SWB and $\mathrm{PWB}$ are stable adsorbents over a wide $\mathrm{pH}$ range. Independent of the origin of this insignificant effect of the $\mathrm{pH}$, this finding is quite meaningful in the adsorption process application since it makes complicated $\mathrm{pH}$ adjustment of the effluent before treatment unnecessary.

As a result, $\mathrm{pH}$ was not adjusted during adsorption experiments to simulate real treatment condition of industrial effluents.

\subsubsection{Effect of Temperature}

The effect of temperature on MB dye adsorption onto SWB and PWB was conducted at 5 different temperatures ranging from 303 to $343 \mathrm{~K}$.

Figure 11 shows that the removal percentage of $M B$ increased with the increase in temperature, indicating that $\mathrm{MB}$ adsorption on both adsorbent surfaces was favored at higher temperatures. The increase in adsorption with increasing 


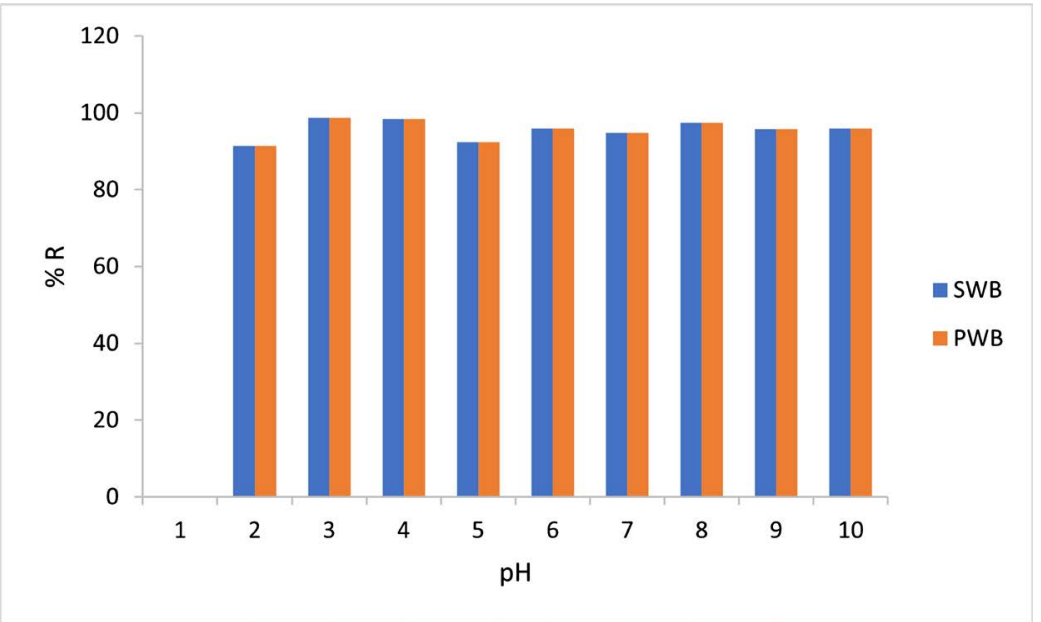

Figure 10. Effect of $\mathrm{pH}$ on the adsorption of MB by SWB and PWB.

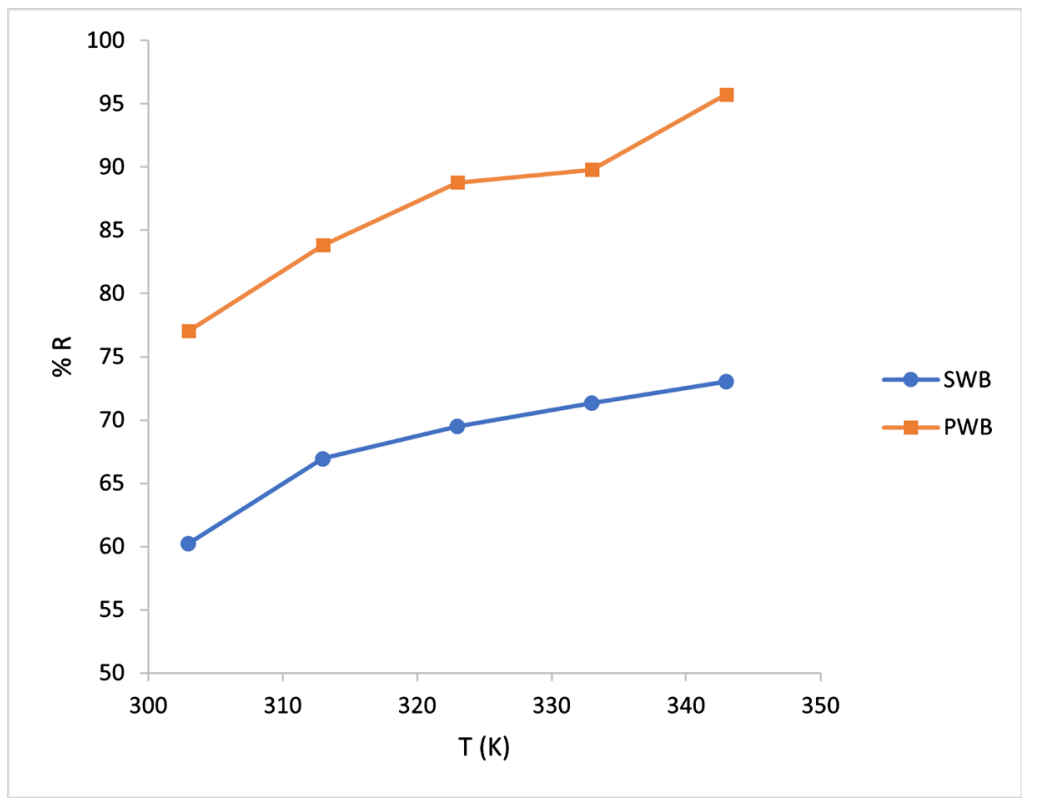

Figure 11. Effect of temperature on the adsorption of MB by TOAPV ${ }_{3} \mathrm{~W}_{9} @$ clay.

temperature indicated the endothermic nature of the adsorption process.

\subsubsection{Effect of Ionic Strength}

The study the effect of salts on the adsorption of dyes is important since wastewater contains different concentrations of salts Figure 12 shows the influence of salt concentration on $\mathrm{MB}$ adsorption onto SWB and PWB. As a whole, the presence of salts reduced the capacities of SWB and PWB on adsorbing MB dye. Both the \% removal and the adsorption capacity of the POM-IL modified bentonite began to decrease when high concentrations of salts were added. This could be partly ascribed to the competitive adsorption between $\mathrm{Na}^{+}, \mathrm{K}^{+}$and $\mathrm{MB}$ cations for available active sites. As shown in Figure 12, the reduced affinity between negatively charged POM-IL modified bentonite and MB cationic dye observed in presence of $\mathrm{KCl}$ is due $\mathrm{K}^{+}$smaller hydrated radius $(2.32 \AA)$ than $\mathrm{Na}^{+}$ 
(2.76 ̊); in this case $\mathrm{K}^{+}$could easily occupy more adsorption sites and could not as easily be leached. Similar results were reported by De Castro et al. when studying the adsorption of MB onto EDTA modified bentonite [27].

It is noticed that $\mathrm{KCl}$ inhibiting effect on the adsorption of $\mathrm{MB}$ is more pronounced in the case of SWB compared to PWB (Figure 12 and Figure 13).

The effect of chloride and nitrate anions on the $\mathrm{MB}$ adsorption is comparable Figure 13, because these negatively charged anions can compete with the bentonite as sites for electrostatic attraction and disrupt MB adsorption [27].

\subsection{Kinetic Study}

Adsorption kinetic describes the solute uptake rate and evidently this rate controls the residence time of adsorbate uptake at solid-solution interface. Two models were used to evaluate adsorption kinetics which are Pseudo-first order and Pseudo-second order kinetic models.

\subsubsection{Pseudo First Order (Lagergren Model)}

This model is one of the most extensively used models to describe the adsorption kinetics. The equation for pseudo-first order is:

$$
\frac{\mathrm{d} t}{\mathrm{~d} Q}=k_{1}\left(Q_{e}-Q_{t}\right)
$$

$Q_{t}$ and $Q_{e}$ are dye amount adsorbed $(\mathrm{mg} / \mathrm{g})$ at time, $t(\mathrm{~min})$ and at equilibrium, respectively, $k_{1}$ is the rate constant of adsorption $\left(\mathrm{min}^{-1}\right)$.
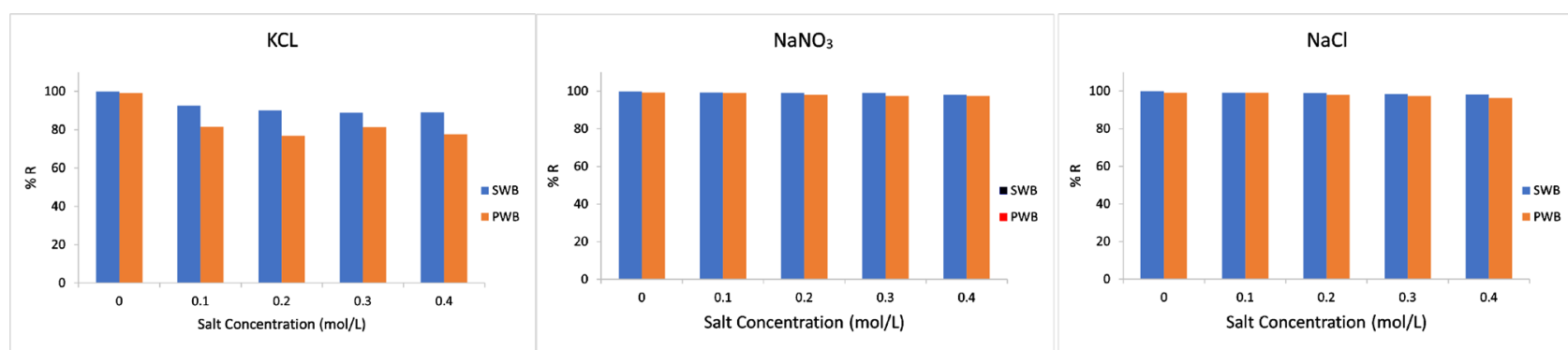

Figure 12. Effects of ionic strength on MB adsorption on SWB and PWB.
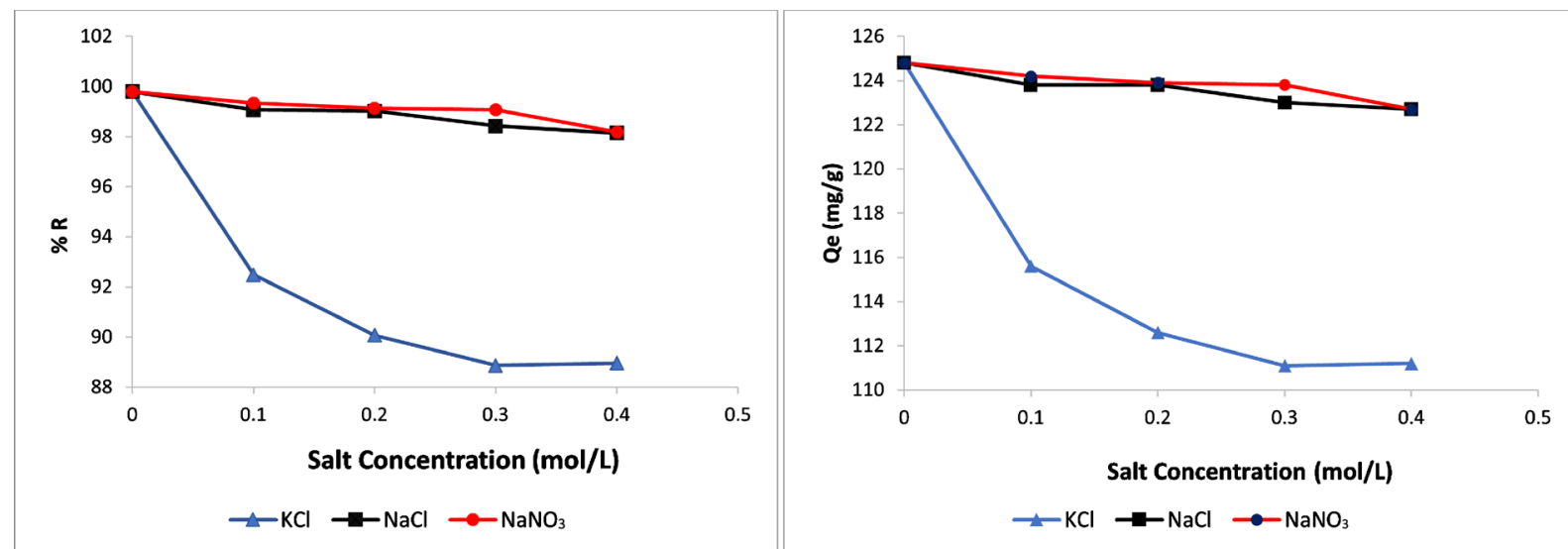

Figure 13. Effects of ionic strength on MB adsorption onto SWB. 
The linear form for pseudo first order can be expressed as:

$$
\ln \left(Q_{e}-Q_{t}\right)=\ln Q_{e}-k_{1} t
$$

When plot of $\ln \left(Q_{e}-Q_{t}\right)$ vs $t$ drawn, $Q_{e}$ and $k_{1}$ values can be obtained from intercept and slope respectively.

\subsubsection{Pseudo-Second Order Model}

Pseudo-second order suggests that the uptake process is due to chemisorption and has the general form as:

$$
Q_{t}=\frac{k_{2} Q_{e}^{2}}{1+k_{2} Q_{e} t}
$$

Mathematically it can also be expressed as follows:

$$
\frac{t}{Q_{t}}=\frac{t}{Q_{e}}+\frac{1}{k_{2} Q_{e}^{2}}
$$

where $k_{2}((\mathrm{~g} / \mathrm{mg}) / \mathrm{min})$ is the constant for second order, $Q_{e}(\mathrm{mg} / \mathrm{g})$ and $Q_{t}(\mathrm{mg} / \mathrm{g})$ the amount of dye adsorbed at equilibrium and any time respectively.

The kinetics of MB dye adsorption onto SWB and PWB were analyzed using pseudo-first-order PFO model (Equation (4)) and pseudo-second order PSO model (Equation (6)).

By applying the two kinetic model, it was found that the plot of $t / q_{t} \mathrm{vs}$. $t$ for PSO model fit for the whole range of contact time for both adsorbent, with excellent linearity Figure 14 . On the other hand plots of $\ln \left(Q_{e}-Q_{t}\right)$ vs. $t$ displayed less-linearity.

The kinetic parameters for PFO and PSO were calculated and tabulated in Table 3.

The real test for the validity of the kinetic model arises from the comparison between the experimentally determined $q_{e}$ and the calculated $q_{e}$ [28] [29]. According to the reported results it is clear that in the PSO kinetic model, the $Q_{e} c a l$ is very close to the $q_{e} \exp$ values. In addition, the $\mathrm{R}^{2}$ values $>0.99$ for the PSO model were higher than those obtained in PFO model. Moreover, in pseudo-second-order a trend was observed with the rate constants, $k_{2}$ generally decreased as the initial concentration increases, which is due to the occupation of active sites. As a result of the above-mentioned reasons, it can be concluded that
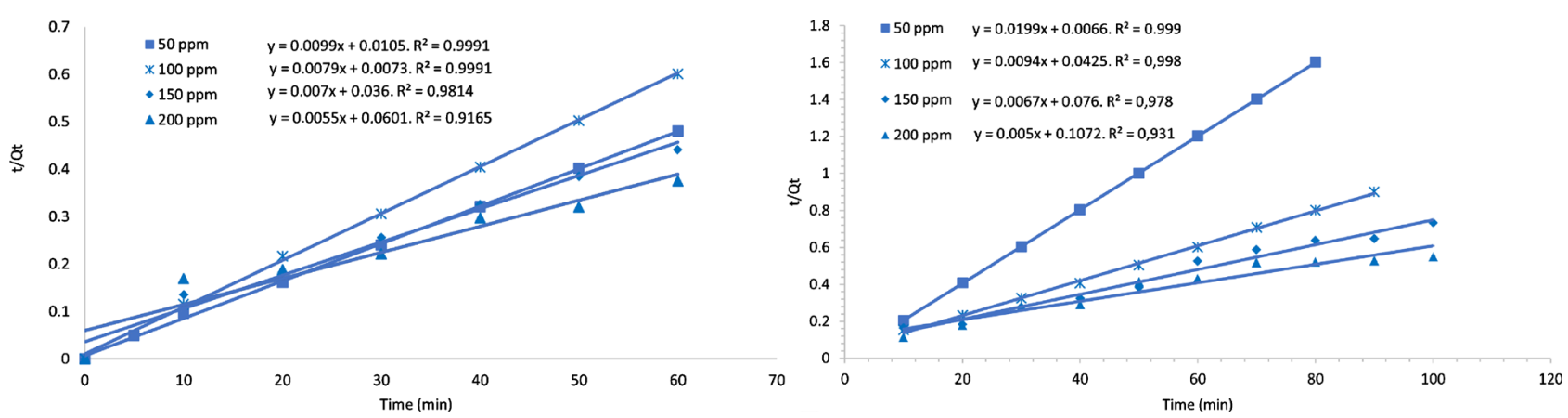

Figure 14. Pseudo-second-order kinetics plots for adsorption onto SWB (A) and PWB (B). 
Table 3. Kinetic parameters for PFO and PSO models.

\begin{tabular}{|c|c|c|c|c|c|c|c|c|}
\hline \multirow[b]{2}{*}{ Adsorbent } & \multirow{2}{*}{$\begin{array}{c}C_{0} \\
(\mathrm{mg} / \mathrm{L})\end{array}$} & \multirow{2}{*}{$\begin{array}{l}Q_{e} \operatorname{Exp} \\
(\mathrm{mg} / \mathrm{g})\end{array}$} & \multicolumn{3}{|c|}{ Pseudo -first-order kinetic } & \multicolumn{3}{|c|}{ pseudo-second-order kinetic } \\
\hline & & & $\begin{array}{c}k_{1} \\
\left(\min ^{-1}\right)\end{array}$ & $\begin{array}{l}Q_{e} \mathrm{Cal} \\
(\mathrm{mg} / \mathrm{g})\end{array}$ & $R^{2}$ & $\begin{array}{c}k_{2} \\
(\mathrm{~g} / \mathrm{mg} \min )\end{array}$ & $\begin{array}{l}Q_{e} \mathrm{Cal} \\
(\mathrm{mg} / \mathrm{g})\end{array}$ & $R^{2}$ \\
\hline \multirow{4}{*}{ PWB } & 50 & 50 & 0.04 & 1.43 & 0.842 & 0.02 & 50 & 0.999 \\
\hline & 100 & 99.9 & 0.0713 & 41.24 & 0.814 & 0.011 & 100 & 0.998 \\
\hline & 150 & 140 & 0.0332 & 87.58 & 0.631 & 0.007 & 142 & 0.978 \\
\hline & 200 & 182 & 0.048 & 349.67 & 0.515 & 0.005 & 200 & 0.931 \\
\hline \multirow{4}{*}{ SWB } & 50 & 50 & 1.040 & 2.83 & 0.365 & 0.02 & 50 & 0,999 \\
\hline & 100 & 100 & 0.058 & 20.82 & 0.715 & 0.011 & 101 & 0.999 \\
\hline & 150 & 147 & 0.063 & 209.9 & 0.813 & 0.001 & 154 & 0.987 \\
\hline & 200 & 195 & 0.052 & 334.4 & 0.565 & 0.005 & 208 & 0.943 \\
\hline
\end{tabular}

the pseudo-second-order model best fit the experimental equilibrium data.

\subsection{Equilibrium Study: Adsorption Isotherm}

Adsorption isotherms are mathematical models that characterize the distribution of the adsorbate types among liquid and adsorbent, based on a set of suppositions that are mainly related to the heterogeneity/homogeneity of adsorbents, the type of coverage and possibility of interaction between the adsorbate types.

They provide clear indication of the surface properties, affinity between the adsorbent and the adsorbate and the adsorption capacity of the adsorbent. Two equilibrium isotherm models were applied to interpret the experimental data for the adsorbent at different concentration to obtain the optimum values of the equilibrium parameters.

\subsubsection{Langmuir Isotherm}

The Langmuir isotherm assumes monolayer adsorption, absence of interaction between adsorbate molecules and homogeneous distribution of active sites on the adsorbent surface [22]. The general equation for Langmuir is:

$$
Q_{e}=\frac{Q_{\max } k_{L} C_{e}}{1+k_{L} C_{e}}
$$

where, $Q_{e}$ is the dye adsorbed amount at equilibrium $(\mathrm{mg} / \mathrm{g}), Q_{\max }$ is the maximum adsorption capacity $(\mathrm{mg} / \mathrm{g}) . k_{L}$ is the constant of Langmuir and $C_{e}$ is dye concentration at equilibrium.

It can also be expressed as:

$$
\frac{C_{e}}{Q_{e}}=\frac{1}{Q_{\max } k_{L}}+\frac{C_{e}}{Q_{\max }}
$$

The value of $\left(1 / Q_{\max }\right)$ and $K_{L}$ can be obtained from linear curve of $\left(C_{e} / Q_{e}\right)$ versus $C_{e}$.

The $R_{L}$ separation factor values provide information about the affinity between adsorbate and adsorbent which can be calculated using the following Eq- 
uation (9):

$$
R_{L}=\frac{1}{1+k_{L} C_{0}}
$$

where $K_{L}$ is the Langmuir constant, $C_{0}(\mathrm{mg} / \mathrm{L})$ is the initial concentration of dye.

Table 4 shows the types of Langmuir isotherm according to $R_{L}$ Values.

\subsubsection{Freundlich Isotherm}

The Freundlich equation is empirical and assumes heterogeneous multilayer adsorption, its mathematical equation is express as:

$$
Q_{e}=k_{f} C_{e}^{1 / n}
$$

where $C_{e}$ is the equilibrium dye concentration $(\mathrm{mg} / \mathrm{L}), Q_{e}$ is the dye adsorbed amount at equilibrium $(\mathrm{mg} / \mathrm{g}), k_{f}$ are the Freundlich constants and $n$ indicative of the extent of the adsorption and the degree of nonlinearity between solution concentration and adsorption intensity.

It can also be linearized in logarithmic form as shown below:

$$
\log Q_{e}=\log k_{f}+\frac{1}{n} \log C_{e}
$$

The value of $(1 / n)$ and $\log k_{f}$ can be calculated from slope and the intercept respectively from linear plot of $\log Q_{e}$ verses $\log C_{e}$.

Table 5 summarizes the calculated coefficients of determination $\left(R^{2}\right)$ and model parameters of the Langmuir and Freundlich isotherms. The results show clearly that the Langmuir isotherm $\left(R^{2}>0.98\right.$ for SWB and $R^{2}>0.97$ for PWB) best fits the equilibrium data for both adsorbents. This indicates that MB adsorption onto SWB and PWB is homogeneous. The maximum adsorption capacities for MB onto SWB and PWB were 113 and $277 \mathrm{mg} \cdot \mathrm{g}^{-1}$, respectively.

To predict the adsorption efficiency, the essential characteristics of Langmuir isotherm was explained in term of a dimensionless constant separation factor $R_{L}$.

As shown in Figure 15(B), the $R_{L}$ values calculated for both SWB and PWB

Table 4. Langmuir isotherm types according to $R_{L}$ Values.

\begin{tabular}{ccccc}
\hline$R_{L}$ & $\left(R_{L}=0\right)$ & $\left(0<R_{L}<1\right)$ & $\left(R_{L}=1\right)$ & $\left(R_{L}>1\right)$ \\
\hline Type of isotherm & irreversible & favorable & linear & unfavorable \\
\hline
\end{tabular}

Table 5. Adsorption Isotherm parameters of the MB on SWB and PWB.

\begin{tabular}{cccc}
\hline Isotherm & Parameter & PWB & SWB \\
\hline \multirow{3}{*}{ Langmuir } & $Q_{\max }(\mathrm{mg} / \mathrm{g})$ & 277.78 & 113.6 \\
& $k_{L}(\mathrm{~L} / \mathrm{mg})$ & 0.24 & 0.16 \\
& $R^{2}$ & 0.972 & 0.985 \\
\hline \multirow{2}{*}{ Freundlich } & $n$ & 13.08 & 5.122 \\
& $k_{f}(\mathrm{mg} / \mathrm{g})$ & 181.22 & 313.2 \\
& $R^{2}$ & 0.879 & 0.860 \\
\hline
\end{tabular}



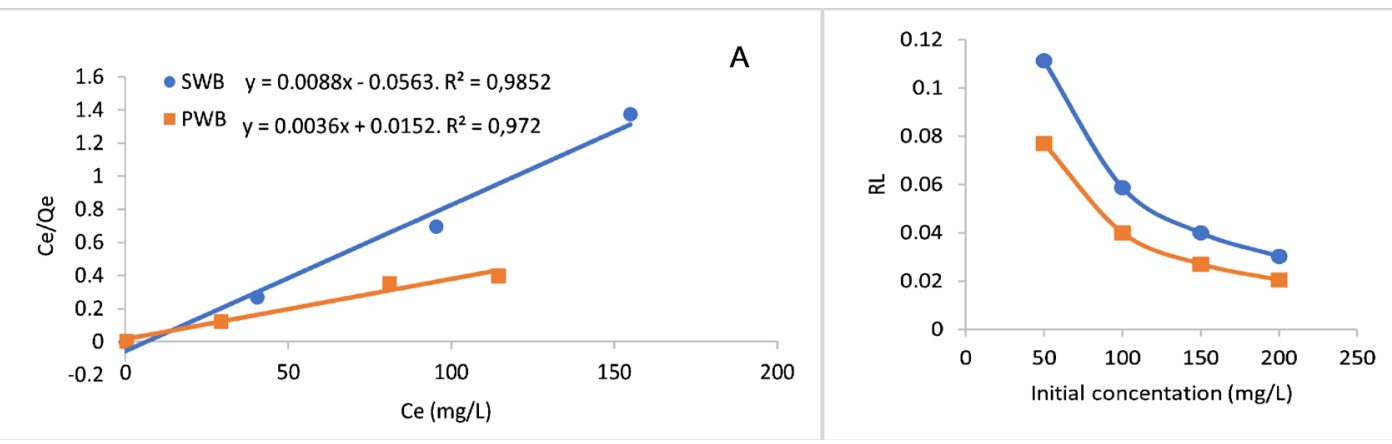

B

Figure 15. (A) Langmuir plot for adsorption of MB onto SWB and PWB. (B) Separation factor values $\left(R_{L}\right)$ at varying initial MB onto SWB and PWB.

were all in the range of $0-1$. Moreover, the $R_{L}$ values were also observed to decrease when the MB dye initial concentration were increasing which means that the adsorption becomes more favorable. This could be due to the increase in driving force when more MB solute was present.

\subsection{Thermodynamic Parameters}

To evaluate the effect of temperature on the adsorption process, the standard Gibbs free energy $\Delta G^{\circ}$, the standard enthalpy $\Delta H^{\circ}$, were calculated using the below Equations:

$$
\begin{gathered}
\Delta G^{\circ}=-R T \ln K_{d} \\
\ln K_{d}=\frac{-\Delta H^{\circ}}{R T}+\frac{\Delta S^{\circ}}{R} \\
K_{d}=\frac{Q_{e}}{C_{e}}
\end{gathered}
$$

where $K_{d}\left(\mathrm{Lg}^{-1}\right)$ is the distribution coefficient, $T(\mathrm{~K})$ : temperature expressed in Kevin and $R$ is Gas constant $\left(8.314 \mathrm{~J} \cdot \mathrm{mol}^{-1} \cdot \mathrm{K}^{-1}\right)$

The standard entropy values $(\mathrm{J} / \mathrm{mol} \mathrm{K}), \Delta S^{\circ}$ were calculated using GibbsHelmholtz equation:

$$
\Delta S^{\circ}=\frac{\Delta H^{\circ}-\Delta G^{\circ}}{T}
$$

The $\Delta G^{\circ}$ values of $\mathrm{MB}$ adsorption onto $\mathrm{SWB}$ and $\mathrm{PWB}$ under different temperatures $(303,313,323,333$ and $343 \mathrm{~K})$ as well as $\Delta H^{\circ}$ and $\Delta S^{\circ}$ values are presented in Table 6.

MB dye adsorption process was spontaneous and endothermic which is proved by the negative value of $\Delta G^{\circ}$ and positive value of $\Delta H^{\circ}$. In addition, the $\Delta G^{\circ}$ values became more negative at higher temperatures making the adsorption more favorable. Positive values of $\Delta S^{\circ}$ indicate that the MB dye adsorption process increased the randomness during the adsorption process and suggest a strong affinity between MB and both adsorbents SWB and PWB.

\subsection{Reusability Test}

The ability of the adsorbents to be reused is a crucial factor. Reusability of the 
Table 6. Thermodynamic parameters of the MB on SWB and PWB.

\begin{tabular}{ccccc}
\hline Adsorbent & $T(\mathrm{~K})$ & $\begin{array}{c}\Delta G^{\circ} \\
(\mathrm{KJ} / \mathrm{mol})\end{array}$ & $\begin{array}{c}\Delta H^{\circ} \\
(\mathrm{KJ} / \mathrm{mol})\end{array}$ & $\begin{array}{c}\Delta \mathcal{S}^{\circ} \\
\left(\mathrm{J} \cdot \mathrm{K}^{-1} \cdot \mathrm{mol}^{-1}\right)\end{array}$ \\
\hline 303 & -0.272 & & \\
PWB & 313 & -1.429 & & \\
& 323 & -2.603 & 35.014 & \\
& 333 & -2.986 & & \\
& 343 & -5.741 & & \\
& 303 & -5.102 & & \\
& 313 & -6.026 & & \\
& 323 & -6.530 & & \\
& 333 & -6.979 & & \\
& 343 & -7.426 & & \\
& & & & \\
& & & & \\
& & & & \\
\end{tabular}



Figure 16. Reusability test for SWB and PWB adsorbent.

adsorbent is usually carried out in order to avoid the cost of a new acquisition and minimizing the amount of waste.

The recycled adsorbent indicated reasonable efficiency (100\%) after one cycle and more than 50\% after four and three runs for SWB and PWB respectively as shown in Figure 16. These results revealed that both SWB and PWB have a good potential as cost-effective adsorbent for removal.

\section{Conclusions}

In this study, new adsorbents based on polyoxometalate ionic liquid supported on Saudi bentonite were prepared and totally characterized. This surface modification was demonstrated to enhance the efficiency of Saudi raw bentonite in adsorbing MB cationic dye from aqueous solutions. In detail, the study was focused on the different parameters affecting the adsorption process, showing the role of the $\mathrm{MB}$ initial concentration, adsorbent dose, $\mathrm{pH}$, temperature values and 
ionic strength. The obtained data show that the adsorption process follows the PSO kinetic model. Adsorption isotherms are described by the Langmuir model confirming the homogeneous monolayer coverage of the adsorbent. The data obtained from the thermodynamic study at different temperatures were used to calculate the thermodynamic parameters and showed that the adsorption process onto POM-IL modified bentonite was found to be spontaneous, endothermic and favorable.

The possibility to perform consecutive cycles of adsorption using the same adsorbent was also presented. Overall, we can conclude that SWB and PWB can be used as an inexpensive, reusable, and environment-friendly treatment option for MB contaminated water. The POM-IL supported bentonite can have potential as multicomponent adsorbent in the removal of heavy metal due to the presence of lacunary polyoxometalate featuring metal binding sites (work in progress) and antibacterial activity owing to the presence of antimicrobial alkyl ammonium cations.

\section{Conflicts of Interest}

The authors declare no conflicts of interest regarding the publication of this paper.

\section{References}

[1] Bagheri, S., Muhd Julkapli, N. and Bee Abd Hamid, S. (2014) Titanium Dioxide as a Catalyst Support in Heterogeneous Catalysis. The Scientific World Journal, 2014, Article ID: 727496. https://doi.org/10.1155/2014/727496

[2] Wan, K.T. and Davis, M.E. (1994) Design and Synthesis of a Heterogeneous Asymmetric Catalyst. Nature, 370, 449-450. https://doi.org/10.1038/370449a0

[3] Rabbani, M., Seghatoleslami, Z.S. and Rahimi, R. (2017) Selective Adsorption of Organic Dye Methylene Blue by $\mathrm{Cs}_{4} \mathrm{H}_{2} \mathrm{PMo}_{11} \mathrm{FeO}_{40} \cdot 6 \mathrm{H}_{2} \mathrm{O}$ in Presence of Methyl Orange and Rhodamine-B. Journal of Molecular Structure, 1146, 113-118. https://doi.org/10.1016/j.molstruc.2017.05.134

[4] Sabarinathan, C., Karuppasamy, P., Vijayakumar, C. and Arumuganathan, T. (2019) Development of Methylene Blue Removal Methodology by Adsorption Using Molecular Polyoxometalate: Kinetics, Thermodynamics and Mechanistic Study. Microchemical Journal, 146, 315-326. https://doi.org/10.1016/j.microc.2019.01.015

[5] Malachova, K., Rybkova, Z., Sezimova, H., Cerven, J. and Novotny, C. (2013) Biodegradation and Detoxification Potential of Rotating Biological Contactor (RBC) with Irpex lacteus for Remediation of Dye-Containing Wastewater. Water Research, 47, 7143-7148. https://doi.org/10.1016/j.watres.2013.07.050

[6] An, S., Liu, X., Yang, L. and Zhang, L. (2015) Enhancement Removal of Crystal Violet Dye Using Magnetic Calcium Ferrite Nanoparticle: Study in Single- and Binary-Solute Systems. Chemical Engineering Research and Design, 94, 726-735. https://doi.org/10.1016/j.cherd.2014.10.013

[7] Wang, Y., Xie, Y., Zhang, Y., Tang, S., Guo, C., Wu, J., et al. (2016) Anionic and Cationic Dyes Adsorption on Porous Poly-Melamine-Formaldehyde Polymer. Chemical Engineering Research and Design, 114, 258-267. https://doi.org/10.1016/j.cherd.2016.08.027 
[8] Ayad, M.M., El-Nasr, A.A. and Stejskal, J. (2012) Kinetics and Isotherm Studies of Methylene Blue Adsorption onto Polyaniline Nanotubes Base/Silica Composite. Journal of Industrial and Engineering Chemistry, 18, 1964-1969. https://doi.org/10.1016/j.jiec.2012.05.012

[9] Vinu, R. and Madras, G. (2009) Kinetics of Sonophotocatalytic Degradation of Anionic Dyes with Nano-TiO 2 . Environmental Science \& Technology, 43, 473-479. https://doi.org/10.1021/es8025648

[10] Salima, A., Benaouda, B., Noureddine, B. and Duclaux, L. (2013) Application of UIva lactuca and Systoceira stricta Algae-Based Activated Carbons to Hazardous Cationic Dyes Removal from Industrial Effluents. Water Research, 47, 3375-3388. https://doi.org/10.1016/j.watres.2013.03.038

[11] Wang, H. and Ren, Z.J. (2014) Bioelectrochemical Metal Recovery from Wastewater: A Review. Water Research, 66, 219-232.

https://doi.org/10.1016/j.watres.2014.08.013

[12] Bailey, S.E., Olin, T.J., Bricka, R.M. and Adrian, D.D. (1999) A Review of Potentially Low-Cost Sorbents for Heavy Metals. Water Research, 33, 2469-2479. https://doi.org/10.1016/S0043-1354(98)00475-8

[13] Eren, E., Afsin, B. and Onal, Y. (2009) Removal of Lead Ions by Acid Activated and Manganese Oxide-Coated Bentonite. Journal of Hazardous Materials, 161, 677-685. https://doi.org/10.1016/j.jhazmat.2008.04.020

[14] Müller, A., Peters, F., Pope, M.T. and Gatteschi, D. (1998) Polyoxometalates: Very Large Clusters-Nanoscale Magnets. Chemical Reviews, 98, 239-272. https://doi.org/10.1021/cr9603946

[15] Pope, M. (1983) Heteropoly and Isopoly Oxometalates. Springer-Verlag, Berlin. https://doi.org/10.1007/978-3-662-12004-0 1

[16] Salavati, H., Tangestaninejad, S., Moghadam, M., Mirkhani, V. and Mohammadpoor-Baltork, I. (2010) Sonocatalytic Oxidation of Olefins Catalyzed by Heteropolyanion-Montmorillonite Nanocomposite. Ultrasonics Sonochemistry, 17, 145-152. https://doi.org/10.1016/j.ultsonch.2009.05.009

[17] Mizuno, N. and Misono, M. (1998) Heterogeneous Catalysis. Chemical Reviews, 98, 199-218. https://doi.org/10.1021/cr960401q

[18] Herrmann, S. (2015) New Synthetic Routes to Polyoxometalate Containing Ionic Liquids: An Investigation of Their Properties. Springer, Berlin. https://doi.org/10.1007/978-3-658-08796-8

[19] Liu, Y., Zheng, R., Han, Z., Gong, K., He, X. and Zhai, X. (2015) Supramolecular Hybrids of Polytungstates and Their Adsorption Properties for Methylene Blue. Journal of Solid State Chemistry, 231, 169-174. https://doi.org/10.1016/j.jssc.2015.08.026

[20] Prabhu, P.P. and Prabhu, B. (2018) A Review on Removal of Heavy Metal Ions from Waste Water Using Natural/Modified Bentonite. MATEC Web of Conferences, Vol. 144, Article No. 02021. https://doi.org/10.1051/matecconf/201814402021

[21] Akpomie, K.G., Dawodu, F.A. and Adebowale, K.O. (2015) Mechanism on the Sorption of Heavy Metals from Binary-Solution by a Low Cost Montmorillonite and Its Desorption Potential. Alexandria Engineering Journal, 54, 757-767. https://doi.org/10.1016/j.aej.2015.03.025

[22] Şahin, Ö., Kaya, M. and Saka, C. (2015) Plasma-Surface Modification on Bentonite Clay to Improve the Performance of Adsorption of Methylene Blue. Applied Clay Science, 116, 46-53. https://doi.org/10.1016/j.clay.2015.08.015 
[23] Oliveira, C.I.R.d., Rocha, M.C.G., Silva, A.L.N.d. and Bertolino, L.C. (2016) Characterization of Bentonite Clays from Cubati, Paraíba (Northeast of Brazil). Cerâmica, 62, 272-277. https://doi.org/10.1590/0366-69132016623631970

[24] Eren, E. and Afsin, B. (2008) An Investigation of $\mathrm{Cu}(\mathrm{II})$ Adsorption by Raw and Acid-Activated Bentonite: A Combined Potentiometric, Thermodynamic, XRD, IR, DTA Study. Journal of Hazardous Materials, 151, 682-691. https://doi.org/10.1016/j.jhazmat.2007.06.040

[25] Tian, N., Zhu, M., Wu, Q., Yan, W. and Yaroslavtsev, A.B. (2014) Preparation and Conductivity of the Keggin-Type Trivanadium-Substituted Tungstosilicic Acid $\mathrm{H}_{7} \mathrm{SiW}_{9} \mathrm{~V}_{3} \mathrm{O}_{40} \cdot 9 \mathrm{H}_{2} \mathrm{O}$. Materials Letters, 115, 165-167. https://doi.org/10.1016/j.matlet.2013.10.052

[26] Wu, Q., Sang, X., Liu, B. and Ponomareva, V. (2005) Synthesis and Performance of High-Proton Conductor Undecatungstochromoindic Heteropoly Acid. Materials Letters, 59, 123-126. https://doi.org/10.1016/j.matlet.2004.07.050

[27] De Castro, M.L.F.A., Abad, M.L.B., Sumalinog, D.A.G., Abarca, R.R.M., Paoprasert, P. and de Luna, M.D.G. (2018) Adsorption of Methylene Blue Dye and Cu(II) Ions on EDTA-Modified Bentonite: Isotherm, Kinetic and Thermodynamic Studies. Sustainable Environment Research, 28, 197-205. https://doi.org/10.1016/j.serj.2018.04.001

[28] McKay, G., Ho, Y. and Ng, J. (1999) Biosorption of Copper from Waste Waters: A Review. Separation and Purification Methods, 28, 87-125. https://doi.org/10.1080/03602549909351645

[29] Allen, S.J., Gan, Q., Matthews, R. and Johnson, P.A. (2005) Kinetic Modeling of the Adsorption of Basic Dyes by Kudzu. Journal of Colloid and Interface Science, 286, 101-109. https://doi.org/10.1016/j.jcis.2004.12.043 